\title{
TÉCNICAS CONSTRUTIVAS UTILIZANDO MADEIRA E SUA EVOLUÇÃO
}

\section{HISTÓRICA}

CONSTRUCTIVE TECHNIQUES USING WOOD AND ITS HISTORICAL EVOLUTION

\author{
Luciano Gustavo souto ${ }^{1}$ \\ Liane da Silva Bueno ${ }^{2}$ \\ Patrícia de Deus e Silva ${ }^{3}$
}

\section{RESUMO}

Este artigo tem como objetivo apresentar um estudo sobre a evolução das técnicas construtivas utilizando a madeira como material estrutural. Através da revisão bibliográfica de literatura existente direcionada a construção civil, foi realizada a descrição do processo evolutivo das técnicas construtivas conhecidas como Loghomes, Pau-a-pique e Enxaimel, relativamente comuns no Brasil e de uma quarta técnica, o Light Wood Frame. Esta apesar de ser amplamente utilizada em várias regiões do mundo ainda não é muito conhecida no Brasil, mas pode-se tornar uma solução viável aos problemas de moradia e produção da construção civil brasileira, já que a madeira vem sendo cada vez mais utilizada como matéria prima no desenvolvimento de novas formas de construção, em vários países. Este estudo se justifica pela necessidade da busca de conhecimento relativo a técnicas construtivas eficientes que agreguem racionalização do uso dos recursos, produção sustentável, redução de custos, qualidade e otimização do tempo. Assim sendo, espera-se que este artigo contribua com a disseminação e o desenvolvimento de conhecimentos necessários, para que os profissionais da construção civil possam iniciar a utilização da madeira industrializada da mesma forma que é feita em outros países.

Palavras-chave: Técnicas construtivas, Madeira na construção civil, evolução histórica.

\footnotetext{
${ }^{1}$ Acadêmico da 7ạ fase do Curso de Engenharia Civil. Universidade alto Vale do Rio do Peixe. E-mail: souto.lucianogustavo@gmail.com.

${ }^{2}$ Mestre em Engenharia Civil. Doutora em Engenharia de Produção. UFSC. Universidade Alto Vale do Rio do Peixe. E-mail: civil@uniarp.edu.br.

${ }^{3}$ Especialista em Metodologia do Ensino de Matemática e Física (UNINTER). Universidade Alto Vale do Rio do Peixe. E-mail: patrícia.silva@uniarp.edu.br.
} 


\section{ABSTRACT}

This article aims to present a study on the evolution of constructive techniques using wood as structural material. Through the bibliographical revision of existing literature directed to civil construction, a description of the evolutionary process of the construction techniques known as Loghomes, Pau-a-pique and Enxaimel, relatively common in Brazil and a fourth technique, Light Wood Frame, was carried out. Although it is widely used in several regions of the world, it is still not very well known in Brazil, but it can become a viable solution to the housing and production problems of Brazilian civil construction, since wood has been increasingly used as a matter In the development of new forms of construction in several countries. This study is justified by the need to search for knowledge related to efficient construction techniques that combine rationalization of resource use, sustainable production, cost reduction, quality and optimization of time. Therefore, this article is expected to contribute to the dissemination and development of the necessary knowledge, so that construction professionals can start using industrialized wood in the same way as in other countries.

Keywords: Constructive techniques, Timber in construction, historical evolution .

\section{INTRODUÇÃO}

A utilização da madeira como material para construção acompanha o homem há milênios, desde o início do processo de sedentarismo da humanidade, com a fundação dos primeiros assentamentos, até as cidades contemporâneas. Ao longo deste período foram desenvolvidas muitas técnicas construtivas utilizando a madeira como elemento estrutural chave, e muitas destas técnicas são aplicadas ainda hoje, porém, utilizando o concreto armado em sua substituição.

Mas a madeira nunca deixou de ser usada, pois apresenta vantagens importantes que dificilmente serão superadas pelo concreto ou qualquer outro material não orgânico:

Boa relação resistência-peso;

Versatilidade para industrialização;

Custo competitivo com o aço e o concreto;

Material 100\% renovável;

Melhor conforto térmico e acústico; 
Produção limpa com menor consumo de energia e consumo de Carbono livre;

Se devidamente dimensionado apresenta excelente comportamento em situação de incêndio.

A madeira apresenta como principais desvantagens a deterioração, provocada por organismos vivos que a consomem, e a sua combustibilidade já que é um material de baixa resistência ao fogo.

Porém ambas desvantagens podem ser facilmente solucionadas. No caso da deterioração existem produtos químicos que aplicados no período correto impedem a proliferação de fungos, bactérias e insetos, pintura específica para madeira auxilia no combate a estes agentes.

Com relação aos incêndios, a madeira em geral é um material combustível mas, é um mal condutor de calor, isso significa que, em um momento de incêndio, uma peça robusta de madeira mantém a temperatura de seu interior por mais tempo, conservando assim, suas propriedades mecânicas. Já as estruturas mais delgadas necessitam de proteção específica, como agente retardantes ao fogo e detalhes construtivos que protegem esta estrutura.

Calil Junior et al. (2003) descreve que diferentemente do aço, madeiras não apresentam distorção quando submetidas a altas temperaturas, dificultando a ruína da estrutura.

As estruturas leves e delgadas conhecidas como Light Wood Frame, se corretamente montadas, ficam isoladas da umidade e do contato com agentes agressores, sendo assim, o revestimento pode servir como agente retardador do fogo.

Anderson (1975), refere sobre a durabilidade das construções em Wood Frame, demonstrando que existem muitas casas no interior dos Estados Unidos da América com mais de 200 anos de idade, construídas quando os primeiros imigrantes chegaram nas regiões.

Com intuito de discutir o uso da madeira na construção civil, principalmente na construção de unidades habitacionais, apresento algumas técnicas construtivas desenvolvidas ao longo da história humana e um comparativo com a realidade brasileira. 


\section{MADEIRA NA CONSTRUÇÃO DA ANTIGUIDADE}

A madeira foi um dos primeiros materiais de construção utilizados pelo homem, registros apresentam seu uso a partir do período Neolítico (entre 12000 a.C e 4000 a.C), principalmente devido à facilidade com que era encontrada e a fácil extração. Provavelmente no início era utilizada como apoio para a cobertura feita de folhas ou capim. A edificação de estruturas com grandes dimensões como armazéns e celeiros obrigou os construtores da antiguidade a buscarem novas formas de utilizar a madeira; surgiram assim as escoras e o travamento longitudinal.
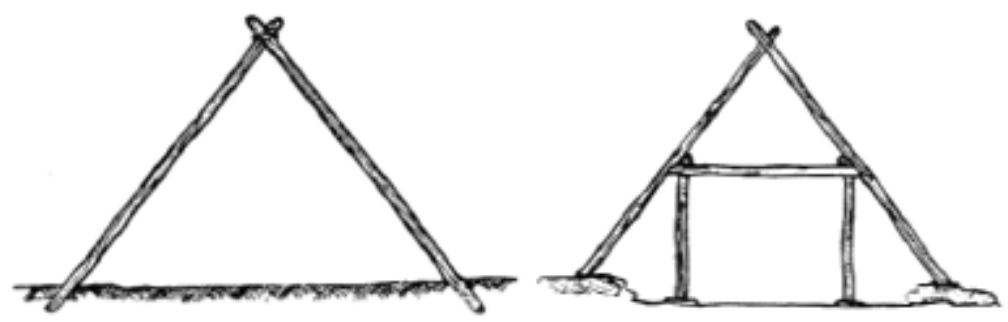

Figura 1 Representação de estruturas simples de madeira (esq.) e estrutura simples utilizando travamento (dir.). Fonte COSTA, A. A. P., p. 5 e p. 6, 2013

Durante milênios o carpinteiro foi o profissional mais requisitado na construção civil. A madeira era utilizada em tudo, desde casas, estruturas defensivas e os templos religiosos, estes últimos apresentando desafios cada vez maiores para o construtor, como vãos e torres cada vez mais altas.

Muitos exemplos de construções religiosas antigas em madeira são encontrados no extremo oriente como os templos xintoístas, no Japão, com mais de 2000 anos de idade que resistem bravamente às intempéries climáticas e aos abalos sísmicos comuns na região.

Na Europa existem ruínas de cidades do período neolítico construídas inteiramente com madeira. Estas casas eram construídas apenas enfileirando e agrupando os troncos das árvores.

\footnotetext{
"Sabe-se que no ano 700 a.C. em Biskupin, na Polónia, existiu uma povoação constituída por casas de troncos. A partir do ano 1000 d.C., na Escandinávia, era frequente a construção de casas de troncos dispostos tanto na horizontal como na vertical." COSTA, A. A. P., p. 7, 2013.
} 
A disposição de troncos na vertical permite resistência à compressão, originária da cobertura, devido a distribuição da carga seguir em paralelo com as fibras da madeira. Mesmo assim, não ganhou muita preferência, pois apresentava pouca estabilidade, devido à falta de travamento, e pouca estanqueidade, enquanto os troncos na horizontal disponibilizam mais estabilidade, porém permanecia a baixa estanqueidade. Utilizavam musgo para preencher os vazios e a pele de animais ou tecidos para cobrir as paredes, obtendo a estanqueidade necessária. Esse sistema de construção mais tarde seria classificado como Loghomes, numa tradução livre: "casas de tronco".
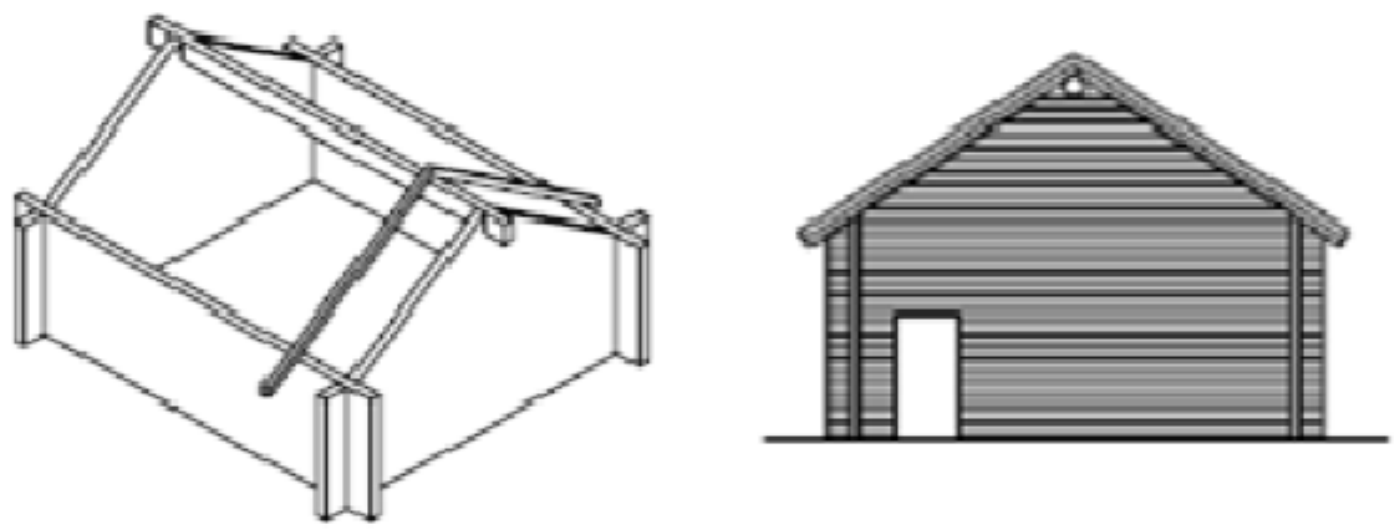

Figura 2 Esquema estrutural de casas de troncos. Fonte COSTA, A. A. P., p. 10, 2013

Durante a Idade Média, com o uso da energia hidráulica, as serrarias passaram a produzir uma quantidade cada vez maior de tábuas retangulares, estas por sua vez permitiam mais estabilidade para a construção e mais estanqueidade e assim, conforto interno. Desta forma as tábuas acabaram substituindo os troncos.

Muitas técnicas foram desenvolvidas neste período com o objetivo de utilizar melhor as características do material, como a resistência a tração e ao cisalhamento, culminando, no final da Idade Média com estruturas de 05 e até 06 pavimentos facilmente encontradas nos burgos.

\section{CONSTRUÇÃO DE MADEIRA NA PENÍNSULA IBÉRICA}

Na península ibérica e nas colônias latino-americanas a construção com madeira era conhecida como pau-a-pique, taipa de mão, barro armado, taipa de 
sopapo, gaiola ou simplesmente, taipa.

Um esqueleto de madeira era formado pelas peças verticais conhecidas como "esteio", pelas peças horizontais superiores o "frechal" e pelas peças horizontais inferiores os "baldrames", este esqueleto era firmemente amarrado em uma estrutura de madeira trançada (pau-a-pique) e esta estrutura era coberta com barro, argila e areia ou outras misturas que permitam estanqueidade a estrutura.

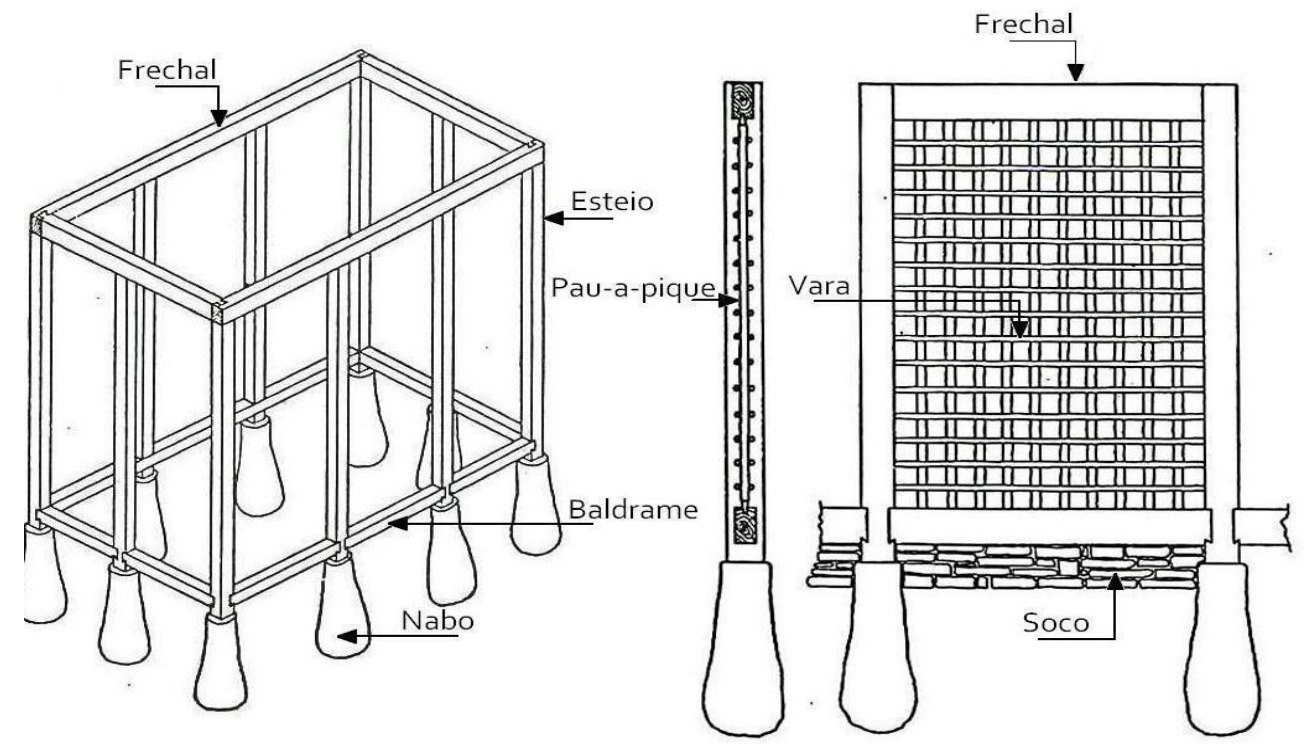

Figura 3 Estrutura de pau-a-pique, a esquerda fundação e componentes estruturais, a direita painel de pau-a-pique, fonte SANTOS P. F. 1951

Durante os séculos XVIII e XIX, nas casas das famílias mais abastadas, esta mistura foi sendo substituída pelo uso da alvenaria. Durante o século XIX o concreto substitui a madeira na função estrutural, sendo que esta começa a ser vista na península ibérica e nas colônias apenas como um material utilizado em construções provisórias, improvisadas ou rústicas, tratado assim, de forma preconceituosa, como um material de segunda e antiquada.

Devido à baixa exigência técnica para a construção e o baixo custo com materiais ainda é comum ver construções em pau-a-pique em regiões rurais do interior do Brasil. Naturalmente não é um método construtivo que disponibiliza bons níveis de conforto aos ocupantes e apresenta riscos estruturais sérios, tendo em vista que a madeira não é devidamente protegida contra as intempéries e provavelmente não recebeu o devido tratamento contra agentes que podem 
provocar a sua deterioração natural.

\section{ENXAIMEL (HEAVY WOOD FRAME)}

Contemporâneo ao pau-a-pique, outra técnica ganha força nos territórios que hoje compõem a moderna Alemanha. Criada durante a Idade Média a técnica construtiva conhecida como "Enxaimel" é precursora das técnicas mais modernas de construção com madeira. No enxaimel as toras das árvores eram cortadas em grandes vigas, robustas e pesadas (Heavy Timber ou Heavy Wood Frame), quadriculares ou retangulares que devidamente encaixadas formam um esqueleto estrutural deixando a construção rígida, sendo muito semelhante com as construções de concreto pré-fabricado modernas.

Como curiosidade, esta estrutura de madeira permitia tanta estabilidade que muitas vezes não existia a necessidade de utilizar estacas fincadas no solo para dar estabilidade, o grande peso da estrutura somado ao pé-direito baixo já permitiam esta estabilidade.

Após a estrutura ser erguida era instalado o telhado. Só após ele ser completamente montado as paredes deveriam ser preenchidas com a vedação disponível, onde inicialmente era utilizado o adobe e após alvenaria, sem função estrutural, apenas para vedação. 


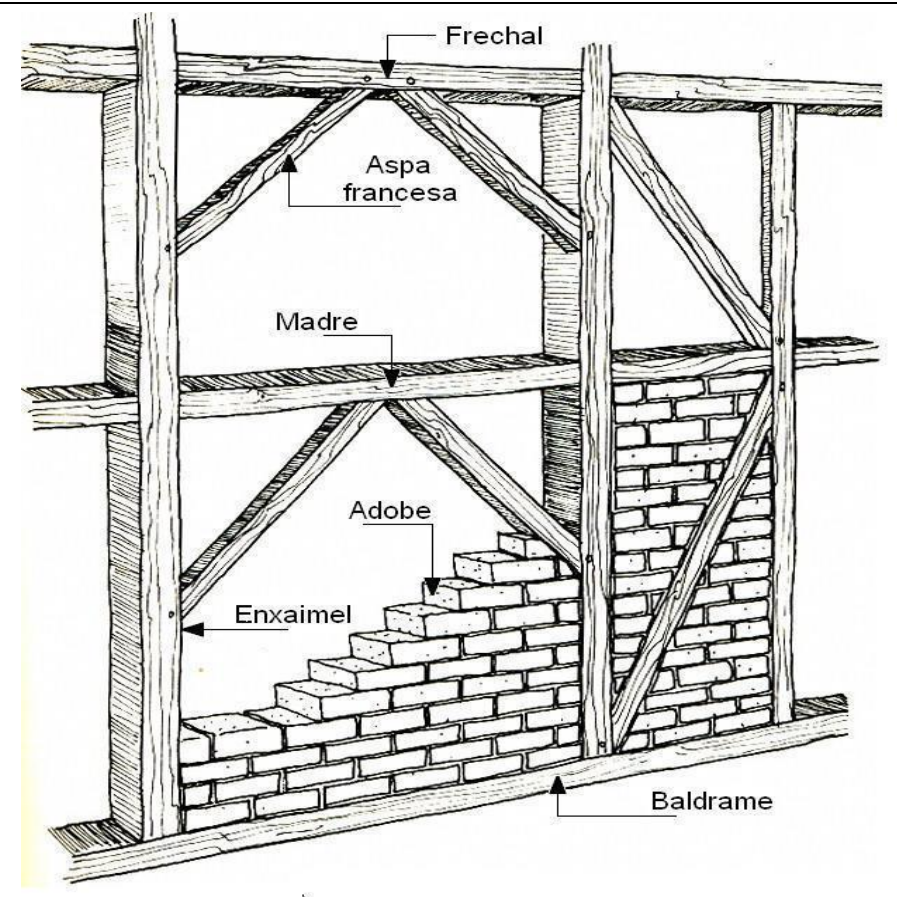

Figura 4 Parede em Enxaimel BARDOU, 1981

Esta técnica continua sendo utilizada em grande parte da Europa com o objetivo de manter traços específicos da cultura germânica. Ela veio com os imigrantes alemães no século XIX para o Brasil, sendo comum em Santa Catarina e no Rio Grande do Sul. As políticas contra a cultura alemã, estabelecidas pelo governo Vargas durante a segunda guerra mundial contribuíram para o abandono desta técnica, sendo substituída pela alvenaria estrutural ou o uso do concreto armado.

Outros colonos de origem europeia levaram esta técnica para a América do Norte. Inicialmente não exigiu modificações, pois existiam grandes reservas de madeira, principalmente de árvores coníferas semelhantes às encontradas na Europa. Mas o crescimento populacional mais rápido do que a construção de novas unidades habitacionais provocou um grave déficit imobiliário, principalmente no oeste americano.

\section{LIGHT WOOD FRAME}

No século XIX, impulsionado pela revolução industrial, possibilitou uma 
produção em massa de madeira serrada e pregos, desenvolve-se um sistema construtivo rápido, eficiente e barato, o Light Wood Frame.

“...o sistema construtivo Wood Framing surgiu quando construtores perceberam que os elementos verticais pouco espaçados, utilizados na vedação em edificações em heavy timber frame, eram suficientemente capazes de suportar as cargas de forma que os pilares robustos de madeira poderiam ser retirados." CARDOSO, L. A., Pg. 32, 2015.

Conforme a Canada Mortgage and Housing Corporation (CMHC) (2014), o sistema foi aperfeiçoado ao longo dos anos, evoluindo até o sistema atual o Light Wood Framing que nada mais é do que a combinação de repetidos elementos estruturais tais como perfis, tesouras treliçadas e painéis de madeira que, funcionando em conjunto produzem a rigidez necessária para resistir a cargas verticais e horizontais.

O Light Wood Frame é subdividido em duas formas o Ballon Frame (estrutura em balão) e o Platform Frame System (estrutura em plataforma).

O sistema Ballon Frame foi desenvolvido primeiro. Na prática as fachadas são levantadas com montantes contínuos em toda a sua altura e as vigas de laje ligam-se diretamente nestes montantes, depois são travadas transversalmente por tábuas corridas formando assim os pisos, sendo que as ligações são feitas apenas com pregos.

Como desvantagens, têm a dificuldade em achar peças com o tamanho adequado para formar os montantes, a dificuldade na execução tendo em vista que as partes devem ser erguidas ao mesmo tempo e por fim o comportamento com relação ao fogo. Como as partes formam uma continuidade total entre os pisos, um incêndio que danifique uma pequena parte da estrutura pode provocar um colapso total desta.

O Platform Frame é a evolução do Ballon Frame, e foi desenvolvido para corrigir as falhas do sistema anterior. Inicialmente os sistemas são bem semelhantes, montantes verticais espaçados a uma distância em média de $60 \mathrm{~cm}$, são travados por vigas horizontais. A principal diferença é o tamanho destes montantes verticais, como foi apresentado anteriormente no Ballon Frame o montante têm a altura total da fachada (1,2,3 pisos) já no Platform Frame os montantes têm a altura de um piso apenas e após erguidos eles são revestidos por 
estruturas de madeira processada ou madeira engenheirada, e esse revestimento garante o funcionamento de toda a estrutura como um corpo único.

O Platform Frame é mais fácil de ser construído pois permite que cada parede seja montada separadamente e após as vigas de laje são colocadas. O comportamento com relação a incêndios também é mais eficiente pois existe uma maior separação entre os pisos.

Detalhe entre pisos

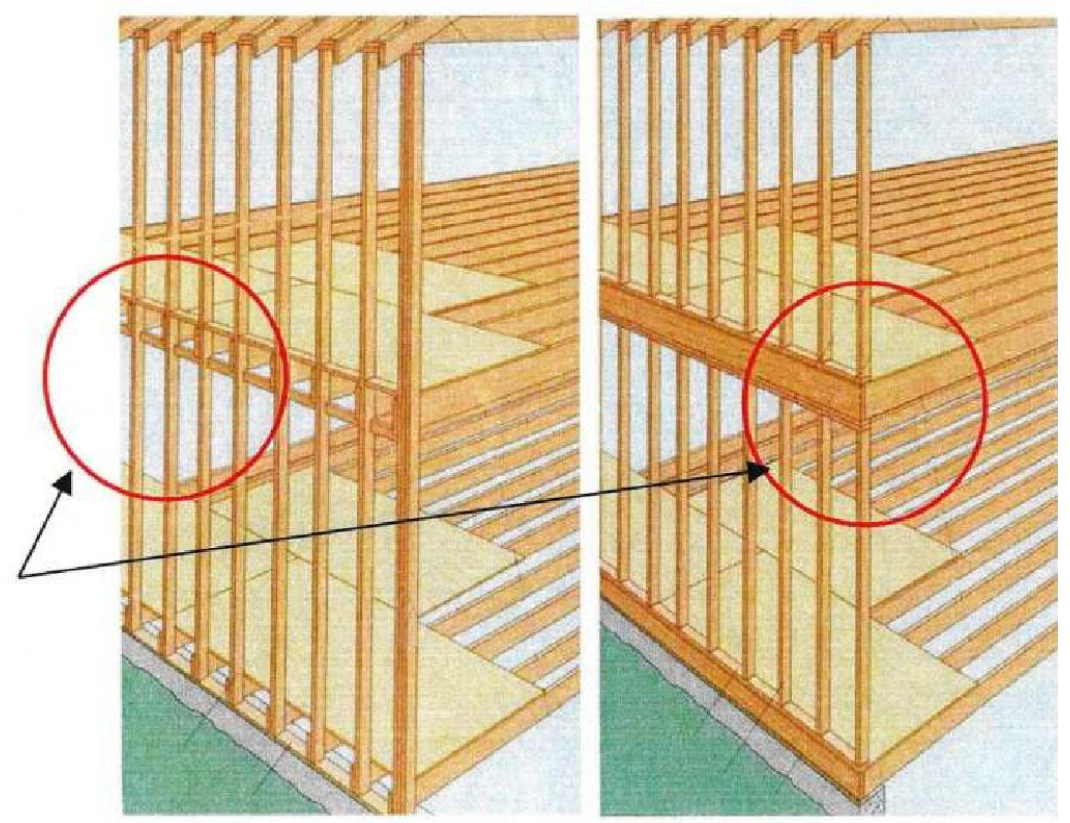

Figura 5 Imagem comparativa a esquerda Ballon Frame e a direita Platform Frame. Fonte: Wagner, p. 22, 2005

No Brasil existe a NBR 7190 de 1997 que regulamenta a construção de estruturas com madeira em geral, principalmente utilizando o Heavy Timber Frame, a NBR 15758 de 2009 e a NBR 14715 de 2010 regulamentam e normatizam o uso do gesso em Drywall. Porém ainda não existe no Brasil nenhuma norma regulamentadora para construções utilizando o Light Wood Frame. Desta forma utiliza-se como referência a norma americana e a norma canadense, por serem mais fáceis de adaptar com a realidade brasileira e porquê muitos dos materiais utilizados são importados destes dois países. Pode-se também, utilizar as normas europeias fazendo as devidas adaptações.

O Light Wood Frame é muito difundido na América do Norte, na Europa, no Chile e no Japão. Apenas nos EUA mais de $90 \%$ das unidades habitacionais são 
construídas tendo o Light Wood Frame como base. Já no Brasil ainda são poucos os empresários investindo nesta técnica, mas existe um movimento grande nos estados do Paraná e Rio Grande do Sul para produzir e difundir a tecnologia com o objetivo de utilizar o Light Wood Frame como solução para o déficit habitacional nestes estados.

Sabe-se que vitórias importantes já foram obtidas: o enquadramento dentro do Programa Brasileiro de Qualidade e Produtividade no Habitat (PBQP-H), possibilitando assim financiamento habitacional com os bancos públicos e a formação de uma bancada na ABNT para criar a norma brasileira em um futuro próximo.

\section{FUTUROS POSSÍVEIS}

Como comentado anteriormente o Platform Frame possibilita a produção industrial parcial ou total. O processo consiste na fabricação em ambiente controlado dos componentes da obra, desta forma é possível produzir apenas um determinado item isolado, os montantes estruturais por exemplo, ou mesmo produzir toda a unidade habitacional, que, posteriormente, é transportado ao local da obra onde ela é instalada em definitivo na fundação mais adequada.

Este processo de industrialização já está bem consolidado nos países onde o Wood Frame é utilizado. No Brasil existem poucas unidades fabris que fazem este processo parcial ou total de industrialização na construção civil. Um ponto interessante ao ser abordada a industrialização é o caso das casas modulares.

\footnotetext{
"Nas casas modulares a coordenação dimensional modular é uma metodologia, que permite que todo o processo de construção seja uniformizado através da racionalização das dimensões dos componentes, otimizando o processo de construção, desde a conceção à construção." COSTA, A. A. P., pg 14, 2013.
}

As casas modulares, talvez sejam a vanguarda da construção civil. São concebidas seguindo o pressuposto de módulos habitacionais que podem funcionar isolados, mas utilizando outros módulos compatíveis, a unidade habitacional pode ser ampliada e completamente modificada, quase como um brinquedo de montar, sendo todo esse processo com baixo custo e de fácil execução. 
A construção pode ser em sistema fechado onde os módulos podem ser combinados, ligados horizontalmente, empilhados, enfim, montados conforme o interesse arquitetônico do projeto. Porém a componente não aceita a instalação de um módulo que não seja completamente compatível, como tentar encaixar peças de dois jogos de montar diferentes. Ou ela pode ser em um sistema aberto onde os módulos podem ser combinados com materiais diferentes formando estruturas únicas e completamente originais.

Este sistema modular ainda está começando a ser desenvolvido em poucos lugares do mundo, e em sua maioria as estruturas são protótipos ligados a universidades ou institutos de pesquisa, mas já estão demonstrando que podem abrir um universo de novas perspectivas para a construção civil.

O Cross Laminated Timber (CLT) foi desenvolvido na última década do século XX e é considerado a maior inovação do uso da madeira nos últimos anos, um processo relativamente simples semelhante ao processo de madeira laminada comum, onde as placas de madeira são coladas umas às outras em um processo combinando alta pressão e cola, mas as semelhanças com o processo tradicional de madeira laminada terminam aí. No CLT as lâminas são coladas em posições ortogonais diferentes em camada, na primeira as lâminas são dispostas horizontalmente na segunda verticalmente e assim sucessivamente.

Desta forma a placa ganha resistência e rigidez mais elevadas seja no plano vertical ou horizontal, assim podendo ser utilizada tanto em paredes dando sustentação à estrutura quando em lajes fornecendo maior capacidade de carga a estrutura. O CLT é utilizado na Europa em conjunto com o Platform Frame, e esta combinação vêm permitindo criar estruturas resistentes o suficiente para passar a barreira de 6 pavimentos comumente usada para limitar o Light Wood Frame. Um exemplo é o edifício Stadthaus localizado na região leste de Londres com 9 pavimentos construído pelo escritório de arquitetura Waught Thistleton Architects apenas com madeira utilizando Light Wood Frame e os painéis de CLT.

"O objetivo principal da Waught Thistleton Architects foi demonstrar que, através do uso de painéis de CLT, é possível dar resposta à necessidade iminente do Reino Unido em construir habitação de grande densidade, inerente ao elevado crescimento urbano, trilhando o caminho do desenvolvimento sustentável. O Stadthaus é, assim, o exemplo pioneiro de arquitetura que aponta para o caminho neutro do carbono na construção." COSTA, A. A. P., Pg. 52, 2013. 


\section{CONCLUSÃO}

O uso da madeira sempre esteve presente na história das construções humanas, como peça estrutural, material para vedação ou componente arquitetônico. Analisando as técnicas mais populares utilizando ela, podemos perceber que, mesmo depois de algumas destas técnicas caírem em desuso elas influenciaram diretamente a forma de se utilizar outros materiais. É muito fácil ver a técnica conhecida como enxaimel e perceber a semelhança com o uso do concreto armado, por exemplo.

Os processos de construção utilizando a madeira como matéria prima são limpos, rápidos e econômicos, utilizam principalmente materiais renováveis, nada ou muito pouco de água, apresentam boa relação resistência/peso, utiliza um material isolante térmico e acústico natural e é amplamente utilizado em países industrializados, ao ponto de existirem estudos para desenvolver seu potencial em novos produtos que podem substituir o concreto, altamente poluidor, na maioria de suas aplicações.

Mas apesar destes fatores, ainda é muito pouco utilizado no Brasil principalmente devido a preconceitos infundados e a falta de capacitação técnica dos profissionais, de todos os níveis, envolvidos com a construção civil. A real necessidade da formação de núcleos especializados e devidamente capacitados para a sua utilização é conhecida. Existem movimentos, principalmente na região sul do Brasil, para a mudança dessa realidade, assim sendo, discutir o potencial do material e as suas aplicações é necessária e para isso devemos conhecer as origens deste material tão comum, a madeira.

\section{REFERÊNCIAS BIBLIOGRÁFICAS}

AMERICAN FOREST \& PAPER ASSOCIATION. Details for Conventional Wood Frame Construction. Washington, DC, 2001.

AMERICAN WOOD COUNCIL. Wood Frame Construction Manual for One-and TwoFamily Dwellings. Leesburg, VA, 2015.

ANDERSON, L. O. Wood Frame House Construction. Washington, DC: Forest Products Laboratory, 1975. 
BARDOU, Patrick e ARZOUMANIAN, Varoujan. Arquitecturas de adobe. Barcelona: Gustavo Gili, 1981.

CANADA MORTAGAGE AND HOUSING CORPORATION. Canadian Wood-Frame Housing Construction, 2014.

CARDOSO, Larriê C., Estudo do Método Construtivo Wood Framing para Construção de Habitações de Interesse Social, Trabalho de conclusão de curso, Universidade Federal de Santa Maria, Santa Maria, RS, Brasil, 2015.

COSTA, Ana A. P., Construção de Edifícios com Cross Laminated Timber

(CLT), Dissertação submetida à avaliação para grau de Mestre em Engenharia Civil Especialização em Construção Civil, Universidade do Porto, Faculdade de Engenharia Civil, Porto, Portugal, 2013.

LOURENÇO, Paulo B. et al. Casas de Madeira. Módulo - Casas de madeira. Da tradição aos novos desafios, Seminário LNEC, Lisboa, 2013

PFEIL, W.; PFEIL, M. Estruturas de Madeira. Rio de Janeiro: LTC, 2003.

SANTOS, Paulo F. Arquitetura religiosa em Ouro Preto. Rio de Janeiro: Kosmos, 1951.

TECVERDE. Curitiba, 2015. Disponível em: <http://www.tecverde.com.br/>. Acesso em 19 Set. 2016.

TECVERDE ENGENHARIA LTDA. DATec N²0: Sistema Construtivo TECVERDE:

Sistema Leve em Madeira. São Paulo, 2013. 
Ignis | Caçador | v.5 | n.2 | p. 47-55 | jul./dez. 2016 